\title{
Revised spectrum of mutations in sarcoglycanopathies
}

\author{
Madiha Trabelsi ${ }^{1,3,4}$, Niloufar Kavian ${ }^{1,3,4}$, Fatma Daoud ${ }^{2,3}$, Virginie Commere ${ }^{1}$, \\ Nathalie Deburgrave ${ }^{1}$, Caroline Beugnet ${ }^{1}$, Stephane Llense $^{1}$, Jean Claude Barbot ${ }^{1}$, \\ Aurélie Vasson ${ }^{1}$, Jean Claude Kaplan ${ }^{1,2,3}$, France Leturcq ${ }^{1,2,3}$ and Jamel Chelly ${ }^{*, 1,2,3}$ \\ ${ }^{1}$ Laboratoire de Biochimie Génétique et Moléculaire, Hôpital Cochin, Paris, France; ${ }^{2}$ Institut Cochin, Université Paris \\ Descartes, Département de Génétique et Développement, CNRS (UMR 8104), Paris, France; ${ }^{3}$ Inserm, U567, \\ Département de Génétique et Développement, Paris, France
}

To define the spectrum of mutations in $\alpha-, \beta-, \gamma-$, and $\delta$-sarcoglycan (SG) genes, we analyzed these genes in 69 probands with clinical and biological criteria compatible with the diagnosis of autosomal recessive limb-girdle muscular dystrophy. For 48 patients, muscle biopsies were available and multiplex western blot analysis of muscle proteins showed significant abnormalities of $\alpha$ - and $\gamma$-SG. Our diagnostic strategy includes multiplex western blot, sequencing of SG genes, multiplex quantitative-fluorescent PCR and RT-PCR analyses. Mutations were detected in 57 patients and homozygous or compound heterozygous mutations were identified in $75 \%(36 / 48)$ of the patients with abnormal western blot, and in $52 \%(11 / 21)$ of the patients without muscle biopsy. Involvement of $\alpha$-SG was demonstrated in $55.3 \%$ of cases (26/47), whereas $\gamma$ - and $\beta$-SG were implicated in $25.5 \%(12 / 47)$ and in $17 \%(8 / 47)$ of cases, respectively. Interestingly, we identified 25 novel mutations, and a significant proportion of these mutations correspond to deletions (identified in 14 patients) of complete exon(s) of $\alpha$ - or $\gamma$-SG genes, and partial duplications (identified in 5 patients) of exon 1 of $\beta$-SG gene. This study highlights the high frequency of exonic deletions of $\alpha$ - and $\gamma$-SG genes, as well as the presence of a hotspot of duplications affecting exon 1 of the $\beta$-SG gene. In addition, protein analysis by multiplex western blot in combination with mutation screening and genotyping results allowed to propose a comprehensive and efficient diagnostic strategy and strongly suggested the implication of additional genes, yet to be identified, in sarcoglycanopathy-like disorders.

European Journal of Human Genetics (2008) 16, 793-803; doi:10.1038/ejhg.2008.9; published online 20 February 2008

Keywords: diagnostic strategy; deletion; duplication; mutation; sarcoglycan

\section{Introduction}

The sarcoglycan (SG) complex in muscle consists of at least four glycosylated transmembrane proteins: $\alpha-, \beta-, \gamma-$, and $\delta$-SG

*Correspondence: Professor Dr J Chelly, Institut Cochin, Laboratoire de Génétique et Physiopathologie des Maladies neurodéveloppementales, CHU Cochin, 24 Rue du Faubourg Saint Jacques, Paris 75014, France. Tel: + 331444124 10; Fax: + 331444124 21;

E-mail: chelly@cochin.inserm.fr

${ }^{4}$ These authors contributed equally to this study.

Received 20 September 2007; revised 18 December 2007; accepted 6 January 2008; published online 20 February 2008 of $50,43,35$, and $35 \mathrm{kDa}$, respectively. ${ }^{1}$ These proteins are part of the large dystrophin-associated glycoprotein (DAG) complex, which is essential for maintaining the link between the cytoskeleton and the extracellular matrix and muscle membrane integrity. ${ }^{2}$ In addition to the structural function, there are now increasing evidence, such as interaction with signaling molecules (nitric oxide synthase and calmodulin), suggesting that DAG complex might play a role in cellular pathways. $^{3,4}$ Genes encoding for $\alpha$ - (SGCA), $\beta$ - (SGCB), $\gamma$ - (SGCG), or $\delta$-SG (SGCD) were mapped to chromosome 17q12-q21.33, 13q12, 4q12, and 5q33, respectively. ${ }^{5-11}$ 
Pathogenic mutations in the SGCA (LGMD 2D, MIM 600119), SGCB (LGMD 2E, MIM 604286), SGCG (LGMD 2C, MIM 353700), and SGCD (LGMD 2F, MIM 601287) (Leiden Muscular Dystrophy pages) are responsible for a subgroup of autosomal recessive limb-girdle muscular dystrophies (LGMD 2C-F) also called sarcoglycanopathies. ${ }^{12,13}$ Though previous studies indicated that the relative frequency of mutations in the four genes can vary from one ethnic population to another, it appears that LGMD $2 \mathrm{D}$ is the most frequent sarcoglycanopathy, ${ }^{12}$ followed by LGMD 2C and LGMD2E, ${ }^{7,9}$ while the most rare is LGMD $2 \mathrm{~F}^{11}$ For instance, $\gamma$-sarcoglycanopathy (LGMD 2C) seems to be found above all in North-African and Gipsy populations, as a result of the founder mutations c. 525 delT $^{14}$ and c.848G $>\mathrm{A}^{15}$ respectively. In SGCA, there is a high predominance of the c. $229 \mathrm{C}>\mathrm{T}$ (R77C) mutation. However, as this mutation was found in unrelated populations and on different haplotype backgrounds, it is believed to result from recurrent mutational events rather than founder effect. ${ }^{16}$

Clinical phenotypes associated with mutations in SG genes are very heterogeneous, though in most cases, patients present with progressive proximal limb-girdle muscle weakness or wasting and elevated serum creatine kinase concentration. ${ }^{17-20}$ In addition to muscle weakness, other clinical features such as cardiomyopathy and respiratory deficiency and retractions are frequently observed. ${ }^{21,22}$

Studies of muscle biopsies, by western blot and immuno cytochemistry from patients with sarcoglycanopathies, showed that mutation in one of the SG genes has consequences on the stability of the entire SG complex and sometimes reduction of dystrophin level as well. Current hypotheses suggest that mutated SG may perturb trafficking, targeting, and/or assembly of the other SG proteins at the sarcolemma that result in a rapid degradation of the mislocated proteins. ${ }^{23}$ As a consequence, the finding of SG protein deficiency on muscle biopsy by immunofluorescence or immunoblotting analyses was shown to be a useful indication that warrants subsequent molecular genetic investigations to establish a correct genetic diagnosis. ${ }^{24,25}$

In this study, we describe the spectrum of mutations in the four SG genes identified in a cohort of 69 patients and report interesting findings that may have significant implications on diagnostic strategies of sarcoglycanopathies. Mutations were detected in 57 patients and among the identified mutations, we found a high proportion of complete exonic deletions of $\alpha$ - or $\gamma$-SG genes and partial duplications of exon 1 of $\beta$-SG gene. In addition, protein analysis by multiplex western blot in combination with mutation screening and genotyping results allowed to propose a comprehensive and efficient diagnostic strategy and strongly suggested the implication of additional genes, yet to be identified, in sarcoglycanopathy-like disorders.

\section{Materials and methods Selection of patients}

Patients with myopathy included in this study were referred to our diagnostic laboratory at Cochin Hospital for diagnostic purposes. The patients and/or their parents provided written informed consent. Selected patients (69 in total) have clinical, biological, and histological features compatible with the diagnosis of recessive LGMD. For all these patients, we excluded the diagnosis of dystrophinopathy and the presence, at a homozygous state, of the three most frequent mutations known in France to be associated with sarcoglycanopathies: c.229C $>$ T (p.Arg77Cys) in $\alpha-S G$ gene; c.525delT (p.Phe175LeufsX20) and c.848G $>$ A (p.Cys283Tyr) in $\gamma$-SG gene. The cohort is made of 53 sporadic and 16 familial cases with at least 2 affected patients, and 6 of these families were consanguineous. Out of the 53 sporadic cases, 10 were also from consanguineous families. Muscle biopsy specimens were available for 48 patients, while for the remaining 21 patients, only DNA was available.

The diagnosis of LGMD was suspected because of the clinical symptoms, elevated serum CK level and histological abnormalities. For the majority of the patients, difficulties for running or climbing stairs and frequent falls were the most common symptoms that characterized the onset of the disease. However, some patients presented only muscle cramps or exercise intolerance. Other clinical features such as calf hypertrophy and cardiomyopathy were also observed. On the basis of their age at presentation, the evaluation of clinical symptoms, and progression of the disease, patients were classified into those with mild LGMD if they presented after 10 years of age with slow illness course without, or with a late, wheelchair confinement (21 patients), and those with severe LGMD (Duchenne-like phenotype) if they presented at or before the age of 10 years, and rapid illness course leading to an early wheelchair dependence (42 patients). A third subgroup included six patients with severe LGMD and cardiomyopathy.

\section{Mutliplex western blot analysis}

Muscle protein analysis was performed on muscle surgical biopsy samples by multiplex western blot method using procedure previously described by Anderson and Davison ${ }^{26}$ and Deburgrave et al. ${ }^{27}$ For some patients, protein extracts (and total RNA) were prepared from 15 to 20 histological sections of muscle biopsies embedded and frozen for immunohistological studies. Monoclonal antibodies used for multiplex western blots are from Novocastra (Newcastle, UK; www.novocastra.co.uk). For multiplex western blots, combinations of antibodies are as follows: (1) multiplex A includes the antibodies Dys8/6C5 (NCL-DYS2/dystrophin C-ter), Cal3c/2A2 (NCL-CALP-12A2/calpain 3 exon 8), 35DAG/21B5 (NCL- $\gamma$-SARC/ $\gamma$-SG), and Ham1/7B6 (NCLHamlet/dysferlin); (2) multiplex B includes the antibodies 
Dys4/6D3 (NCL-DYS1/dystrophin rod domain), Calp3d/ 2C4 (NCL-CALP-2C4/calpain 3 exon 1), and ad1/20A6 $(\mathrm{NCL}-\alpha-\mathrm{SARC} / \alpha-\mathrm{SG})$.

\section{Sequencing analysis}

Genomic DNA was extracted from patient's whole blood using standard procedures. Exons and flanking intronic sequences of the four SG genes were amplified by PCR using primers indicated in Supplementary Table S1 and sequenced using the Big Dye Terminator-1 Applied Biosystems kit and the Applied Biosystems 3130 XL sequencer (Applied Biosystems, Foster City, CA, USA).

\section{Quantitative fluorescent PCR analysis}

To search for copy number changes in exons of $\alpha$ - and $\gamma$-SG genes by multiplex quantitative fluorescent PCR (QF-PCR), we adapted the fluorescent dosage multiplex PCR method described by Yau et al. ${ }^{28}$ Briefly, amplifications were performed, according to standard procedure in $25 \mu \mathrm{l}$ volumes containing $100 \mathrm{ng}$ of genomic DNA and $2 \mathrm{pmol}$ of each of the Ned-coupled forward and reverse primers corresponding to the nine exons of $\alpha$-SG gene, or the Hexlabeled ones corresponding to the eight exons of $\gamma$-SG gene. Size of amplified fragments, exonic primer positions, and sequences are indicated in Supplementary Table S2. Fluorescent PCR products obtained after 18 cycles (during the exponential phase of PCR amplification) were analyzed using the Applied Biosystems $3130 \mathrm{XL}$ sequencer and the Genemapper software v4.0 (Applied Biosystems). Copy number (or dosage) of amplified exons was determined by comparison of each exon peak area of a given sample against one another, and against those from controls. Series of dosage quotients (DQs) were calculated for each exon and number of copies for each exon was deduced as previously reported ${ }^{28}$ Deletions detected by QF-PCR in patients for whom muscle's RNAs was available were subsequently confirmed by RT-PCR.

\section{RNA extraction and RT-PCR analysis}

Total muscle RNA extraction using the RNA Plus kit (Q-BIOgene, Carlsbad, CA, USA) was performed according to the manufacturer's protocol. For each gene, overlapping fragments covering the full-length mRNA were amplified by RT-PCR using primers described in Supplementary Table S3. Amplified cDNA fragments were analyzed by electrophoresis on a $2 \%$ agarose gel and direct sequencing using Applied Biosystems 3130 XL sequencer.

\section{Genotyping study}

Highly informative (CA)n polymorphic microsatellite markers, with a mean heterozygosity $>70 \%$, located in the vicinity, or within the various SG genes were used to genotype consanguineous families. Microsatellite markers are as follows: D17S1795, D17S1869, D17S1815, and D17S1820 for $\alpha$-SG gene; D4S1577 and D4S2996 for $\beta$-SG gene; D13S1236, D13S1275, D13S232, and D13S1243 for $\gamma$-SG gene; and D5S662, D5S487, D5S1439, and D5S2112 for $\delta$-SG gene. Details concerning these markers could be found in the online database at http://genome.ucsc.edu/ cgi-bin/hgGateway. Analysis of microsatellite markers was performed by fluorescent genotyping procedure, using the Applied Biosystems 3130 XL sequencer and the Genemapper software $\mathrm{v} 4.0$.

\section{Results Multiplex protein profiles and mutation detection rates}

When muscle biopsy specimen is available, the first step of our diagnostic strategy is based on muscle protein analysis by multiplex western blot. Such analysis showed for the 48 patients, of the 69 included in this cohort, significant quantitative abnormalities of $\alpha$ - and $\gamma$-SG proteins (Table 1), and normal profiles for dysferlin and calpain proteins. Dystrophin protein was also normal in most cases, though a slight decrease of its amount was observed in 12 patients (23\%). In total, 10 of the 12 patients have a severe form of myopathy. The clinical classifications of all patients and immunoblotting results were shown in Table 2. According to the residual amount of $\alpha$ - and $\gamma$-SG proteins, four different protein profiles (Table 1 and Figure 1) could be distinguished: (i) absence of $\alpha$ - and $\gamma$-SG (23 patients), (ii) absence of $\alpha$ - and reduced level of $\gamma$-SG (6 patients),

Table 1 Results of immunoblotting for $\alpha$ - and $\gamma$-sarcoglycans, and number (frequency) of sarcoglycan gene mutations in 69 patients with myopathy

\begin{tabular}{lcccccc}
\hline $\begin{array}{l}\text { Sarcoglycan gene } \\
\text { (SG) mutations }\end{array}$ & \multicolumn{9}{c}{ Multiplex western blot (WB) results (48) } & WB not done & Patients with confirmed diagnosis \\
& $\alpha=0 \gamma=0$ & $\alpha=0 \gamma=\downarrow$ & $\alpha \downarrow \gamma=0$ & $\alpha \downarrow \gamma \downarrow$ & \\
(homozygous or compound heterozygous) (\%)
\end{tabular}

For western blot results, absence or reduced level of protein is indicated by 0 or $\downarrow$, respectively. Numbers between [ ] indicate the number of patients for whom only one mutation was identified. DH indicates the double heterozygous patient. 
Table 2 Sarcoglycan gene mutations in patients with abnormal results of $\alpha$ - and $\gamma$-sarcoglycan immunoblotting and in patients for whom muscle protein analysis was not performed (NP)

\begin{tabular}{|c|c|c|c|c|c|c|}
\hline \multirow[b]{2}{*}{ Patient no. } & \multirow[b]{2}{*}{ Clinical form } & \multirow{2}{*}{$\begin{array}{l}\text { Family data/ } \\
\text { consanguinity }\end{array}$} & \multicolumn{2}{|c|}{$\begin{array}{l}\text { Sarcoglycan } \\
\text { deficiency }\end{array}$} & \multirow[b]{2}{*}{ Nucleotide change } & \multirow{2}{*}{$\begin{array}{l}\text { Amino-acid substitution or other consequence } \\
\text { of mutation }\end{array}$} \\
\hline & & & $\alpha-S G$ & $\gamma-S G$ & & \\
\hline \multicolumn{7}{|c|}{ Mutation in the $\alpha$-sarcoglycan gene } \\
\hline 1 & SLGMD+CM & Sporadic/no & 0 & 0 & c.86dupA/c.229C > T & p.His29GInfsX14/p.Arg77Cys \\
\hline 2 & SLGMD & Sporadic/no & 0 & 0 & c. $92 \mathrm{~T}>\mathrm{C} / \mathrm{c} .583 \mathrm{G}>\mathrm{A}$ & p.Leu31Pro/p.Gly195Ärg \\
\hline 3 & SLGMD+CM & Sporadic/NA & 0 & 0 & c. $278 \mathrm{C}>\mathrm{T} / \mathrm{c} .301 \mathrm{C}>\mathrm{T}$ & p.Ala93Val/p.Gln101X \\
\hline 4 & MLGMD & Sporadic/no & 0 & 0 & c. $220 \mathrm{C}>\mathrm{T} / \mathrm{c} .229 \mathrm{C}>\mathrm{T}$ & p.Arg74Trp/p.Arg77Cys \\
\hline 5 & SLGMD & Sporadic/no & 0 & 0 & c. $220 \mathrm{C}>\mathrm{T} / \mathrm{c} .229 \mathrm{C}>\mathrm{T}$ & p.Arg74Trp/p.Arg77Cys \\
\hline 6 & MLGMD & Sporadic/no & 0 & 0 & c. $229 \mathrm{C}>\mathrm{T} / \mathrm{c} .850 \mathrm{C}>\mathrm{T}$ & p.Arg77Cys/p.Arg284Cys \\
\hline 7 & SLGMD & Sporadic/no & 0 & 0 & c. $229 \mathrm{C}>\mathrm{T} / \mathrm{c} .748-11 \_748-12$ delinsAA & p.Arg77Cys/sp (splice of exon 7) \\
\hline 8 & SLGMD & Sporadic/NA & 0 & 0 & c. $421 \mathrm{C}>\mathrm{A} / \mathrm{ND}$ & p.Arg141Ser/ND \\
\hline 9 & SLGMD+CM & Sporadic/NA & 0 & 0 & c.409G >A/c.409G >A & p.Glu137Lys/p.Glu137Lys \\
\hline 10 & SLGMD & Familial/NA & 0 & 0 & c. $101 \mathrm{G}>\mathrm{A} / \mathrm{c} .229 \mathrm{C}>\mathrm{T}$ & p.Arg34His/p.Arg77Cys \\
\hline 11 & SLGMD & Sporadic/yes & 0 & 0 & c. $385+1 \mathrm{G}>\mathrm{T} / \mathrm{c} .385+1 \mathrm{G}>\mathrm{T}$ & sp/sp (splice of exon 4) \\
\hline 12 & SLGMD & Sporadic/no & 0 & $\downarrow$ & c. $409 \mathrm{G}>\mathrm{A} / \mathrm{c} .409 \mathrm{G}>\mathrm{A}$ & p.Glu137Lys/p.Glu137Ĺys \\
\hline 13 & SLGMD & Sporadic/no & 0 & $\downarrow$ & c. $409 \mathrm{G}>\mathrm{A} / \mathrm{c} .518 \mathrm{~T}>\mathrm{C}$ & p.Glu137Lys/p.Leu173Pro \\
\hline 14 & SLGMD & Sporadic/yes & 0 & $\downarrow$ & c.530delC/c.530delC & p.Ser177LeufsX32/p.Ser177LeufsX32 \\
\hline 15 & SLGMD & Familial/no & 0 & $\downarrow$ & c. $229 \mathrm{C}>\mathrm{T} /$ c. $37+3 \mathrm{~A}>\mathrm{T}$ & p.Arg77Cys/sp (disruption of exon 1 splice) \\
\hline 16 & SLGMD & Sporadic/no & $\downarrow$ & 0 & c.87_111del/c.739G >A & p.His29HisfsX9/p.Val247Met \\
\hline 17 & SLGMD & Sporadic/NA & $\downarrow$ & 0 & $\begin{array}{l}\text { c. } 229 \mathrm{C}>\mathrm{T} / \mathrm{c} .748-? .983+? \text { del (heterozygous } \\
\text { deletion exons } 7 \text { and } 8 \text { ) }\end{array}$ & p.Arg77Cys/fs \\
\hline 18 & MLGMD & Sporadic/no & $\downarrow$ & $\downarrow$ & c. $229 \mathrm{C}>\mathrm{T} / \mathrm{c} .850 \mathrm{C}>\mathrm{T}$ & p.Arg77Cys/p.Arg284Cys \\
\hline 19 & MLGMD & Sporadic/NA & $\downarrow$ & $\downarrow$ & $\begin{array}{l}\text { c.739G }>\text { A/c.748-? }-983+\text { ? del (heterozygous } \\
\text { deletion of exons } 7 \text { and } 8 \text { ) }\end{array}$ & p.Val247Met/fs \\
\hline 20 & MLGMD & Familial/no & $\downarrow$ & $\downarrow$ & c. $850 \mathrm{C}>\mathrm{T} / \mathrm{c} .850 \mathrm{C}>\mathrm{T}$ & p.Arg284Cys/p.Arg284Cys \\
\hline 21 & SLGMD & Sporadic/no & $\downarrow$ & $\downarrow$ & c. $101 \mathrm{G}>\mathrm{A} / \mathrm{c} .623 \mathrm{C}>\mathrm{T}$ & p.Arg34His/p.Thr208lle \\
\hline 22 & SLGMD & Sporadic/yes & $\downarrow$ & $\downarrow$ & c. $157 \mathrm{G}>\mathrm{A} / \mathrm{c} .157 \mathrm{G}>\mathrm{A}$ & p.Ala53Thr/p.Ala53Thr \\
\hline 23 & SLGMD+CM & Familial/yes & $\downarrow$ & $\downarrow$ & c. $229 \mathrm{C}>\mathrm{T} / \mathrm{c} .416 \mathrm{~T}>\mathrm{G}$ & p.Arg77Cys/p.Leu139Arg \\
\hline 24 & SLGMD & Sporadic/no & NP & NP & c.92T $>C / c .92 T>C$ & p.Leu31Pro/p.Leu31Pro \\
\hline 25 & SLGMD & Familial/yes & NP & NP & c. $37+3 \mathrm{~A}>\mathrm{T} / \mathrm{c} .37+3 \mathrm{~A}>\mathrm{T}$ & sp/sp (disruption of exon 1 splice) \\
\hline 26 & SLGMD & Sporadic/yes & NP & NP & c. 229 C $>$ T/c. $644 C>T$ & p.Arg77Cys/p.Ser215Phe \\
\hline 27 & SLGMD & Sporadic/NA & NP & NP & c.86dup A/c.229C > T & p.His29GInfsX14/p.Arg77Cys \\
\hline \multicolumn{7}{|c|}{ Mutation in the $\beta$-sarcoglycan gene } \\
\hline 28 & SLGMD & Familial/no & 0 & 0 & c.128_129insG/c.10(-22_33+?dup) & $\begin{array}{l}\text { p.Gly43GlyfsX4/? (partial duplication of } \\
\text { exon 1) }\end{array}$ \\
\hline 29 & SLGMD & Sporadic/NA & 0 & 0 & c. $341 \mathrm{C}>\mathrm{T} / \mathrm{ND}$ & p.Ser114Phe/ND \\
\hline 30 & MLGMD & Familial/no & 0 & 0 & c.10-22_10dup32/c.10-22_10dup32 & ?/? (partial duplication of exon 1) \\
\hline 31 & MLGMD & Sporadic/no & 0 & $\downarrow$ & c. $341 \mathrm{C}>\mathrm{T} / \mathrm{c} .341 \mathrm{C}>\mathrm{T}$ & p.Ser114Phe/p.Ser114Phe \\
\hline 32 & MLGMD & Sporadic/NA & 0 & $\downarrow$ & c.4-22_4dup26/c.4-22_4dup26 & ?/? (partial duplication of exon 1) \\
\hline 33 & SLGMD+CM & Sporadic/no & $\downarrow$ & $\downarrow$ & c. $341 \mathrm{C}>\mathrm{T} / \mathrm{c} .341 \mathrm{C}>\mathrm{T}$ & p.Ser114Phe/p.Ser114Phe \\
\hline 34 & MLGMD & Sporadic/no & $\downarrow$ & $\downarrow$ & c.212T>G/c.334_337del & p.Leu71Arg/p.GIn112_Val113delinsTyrfsX4 \\
\hline 35 & SLGMD & Familial/NA & NP & NP & c.112_113del/c.112_113del & p.Ser38X/p.Ser38X \\
\hline 36 & SLGMD & Familial/yes & NP & NP & c. $191 \mathrm{~T}>\mathrm{G} / \mathrm{c} .191 \mathrm{~T}>\mathrm{G}$ & p.Leu64X/p.Leu64X \\
\hline 37 & SLGMD & Sporadic/yes & NP & NP & c.10(-22_33+?dup)/ND & fs/ND \\
\hline \multicolumn{7}{|c|}{ Mutation in the $\gamma$-sarcoglycan gene } \\
\hline 38 & SLGMD & Sporadic/NA & 0 & 0 & $\begin{array}{l}\text { c.386-?_578+?del/c.386-?_578+?del } \\
\text { (homozygous deletion of exons } 5 \text { and } 6 \text { ) }\end{array}$ & $\mathrm{fs} / \mathrm{fs}$ \\
\hline 39 & SLGMD & Familial/NA & 0 & 0 & $\begin{array}{l}\text { c.579-?_702+?del/c.579-?_702+?del } \\
\text { (homozygous deletion of exon } 7 \text { ) }\end{array}$ & $\mathrm{fs} / \mathrm{fs}$ \\
\hline 40 & SLGMD & Sporadic/yes & 0 & 0 & $\begin{array}{l}\text { c.196-?_297+?del/c.196-?_297+?del } \\
\text { (homozygous deletion of exon 3) }\end{array}$ & p.Ala66_Val99del/p.Ala66_Val99del \\
\hline 41 & SLGMD & Sporadic/no & 0 & 0 & C.409_417del/ND & p.Asn137_Gln139del/ND \\
\hline 42 & SLGMD & Sporadic/no & $\downarrow$ & 0 & $\begin{array}{l}\text { c. } 13 \mathrm{delC} / \text { c. }-155-?-876+\text { ?del (heterozygous } \\
\text { deletion of the whole gene) }\end{array}$ & p.GIn5SerfsX10/no protein \\
\hline 43 & MLGMD & Sporadic/no & $\downarrow$ & 0 & c.87dupT/c.87dupt & p.Gly30TrpfsX29/p.Gly30TrpfsX29 \\
\hline 44 & SLGMD & Sporadic/NA & 0 & 0 & $\begin{array}{l}\text { c.525delT/c.579-? } 702+\text { ?del (heterozygous } \\
\text { deletion of exon } 7 \text { ) }\end{array}$ & p.Phe175LeufsX20/fs \\
\hline 45 & SLGMD & Familial/yes & $\downarrow$ & 0 & c.525delT/ND & p.Phe175LeufsX20/ND \\
\hline 46 & SLGMD+CM & Familial/yes & $\downarrow$ & 0 & $\begin{array}{l}\text { c.196-?_297+?del/c.196-?_297+?del } \\
\text { (homozygous deletion of exon 3) }\end{array}$ & p.Ala66_Val99del/p.Ala66_Val99del \\
\hline 47 & SLGMD & Familial/yes & $\downarrow$ & $\downarrow$ & $\begin{array}{l}\text { c.703-?_876+?del/ND (heterozygous deletion of } \\
\text { exon 8) }\end{array}$ & p.Leu235_Leu291del/ND \\
\hline 48 & SLGMD & Familial/NA & NP & NP & $\begin{array}{l}\text { c. }-155-?--1+\text { ?del/c. }-155-?-1+\text { - } 1 \text { del } \\
\text { (homozygous deletion of exon } 1 \text { ) }\end{array}$ & ?/? (disrupted expression) \\
\hline 49 & SLGMD & Sporadic/no & NP & NP & $\begin{array}{l}\text { c.386-?_578+?del/c.386-?_578+?del } \\
\text { (homozygous deletion of exons } 5 \text { and 6) }\end{array}$ & $\mathrm{fs} / \mathrm{fs}$ \\
\hline 50 & SLGMD & Sporadic/yes & NP & NP & $\begin{array}{l}\text { c.703-? ?876+?del/ND (heterozygous deletion of } \\
\text { exon 8) }\end{array}$ & p.Leu235_Leu291del/ND \\
\hline 51 & MLGMD & Sporadic/no & NP & NP & $\begin{array}{l}\text { c.196-? } \\
\text { exon 3) }\end{array}$ & p.Ala66_Val99del/ND \\
\hline 52 & MLGMD & Familial/no & NP & NP & c. $-128-122$ delGACAGTT/ND & $? / \mathrm{ND}$ \\
\hline 53 & SLGMD & Sporadic/no & NP & NP & $\begin{array}{l}\text { c.525delT/c.579-?_702+?del (heterozygous } \\
\text { deletion of exon } 7 \text { ) }\end{array}$ & p.Phe175LeufsX20/fs \\
\hline 54 & SLGMD & Sporadic/NA & NP & NP & c.525delT/c.787G >A & p.Phe175LeufsX20/p.Glu263Lys \\
\hline 55 & SLGMD & Sporadic/no & NP & NP & c.525delT/ND & p.Phe175LeufsX20/ND \\
\hline
\end{tabular}


Table 2 (Continued)

\begin{tabular}{|c|c|c|c|c|c|c|}
\hline \multirow[b]{2}{*}{ Patient no. } & \multirow[b]{2}{*}{ Clinical form } & \multirow{2}{*}{$\begin{array}{l}\text { Family data/ } \\
\text { consanguinity }\end{array}$} & \multicolumn{2}{|c|}{$\begin{array}{l}\text { Sarcoglycan } \\
\text { deficiency }\end{array}$} & \multirow[b]{2}{*}{ Nucleotide change } & \multirow{2}{*}{$\begin{array}{l}\text { Amino-acid substitution or other consequence } \\
\text { of mutation }\end{array}$} \\
\hline & & & $\alpha-S G$ & $\gamma-S G$ & & \\
\hline 56 & SLGMD & Familial/no & NP & NP & c.582dupA/c.582dupA & p.Glu195ArgfsX23/p.Glu195ArgfsX23 \\
\hline \multicolumn{7}{|c|}{ Double heterozygous (mutation in $\delta$ - and $\beta$-sarcoglycan genes) } \\
\hline 57 & SLGMD & Sporadic/yes & 0 & 0 & c. $451 \mathrm{~T}>\mathrm{G} / \mathrm{c} .10\left(-22 \_33+?\right.$ dup $)$ & p.Ser151Ala/partial duplication of exon 1 \\
\hline \multicolumn{7}{|c|}{ No mutation detected } \\
\hline 58 & MLGMD & Sporadic/yes & 0 & 0 & & \\
\hline 59 & MLGMD & Sporadic/no & 0 & 0 & & \\
\hline 60 & MLGMD & Sporadic/NA & 0 & 0 & & \\
\hline 61 & MLGMD & Sporadic/no & 0 & 0 & & \\
\hline 62 & MLGMD & Sporadic/NA & $\downarrow$ & 0 & & \\
\hline 63 & MLGMD & Sporadic/no & $\downarrow$ & $\downarrow$ & & \\
\hline 64 & MLGMD & Sporadic/NA & $\downarrow$ & $\downarrow$ & & \\
\hline 65 & SLGMD & Sporadic/yes & NP & NP & & \\
\hline 66 & SLGMD & Sporadic/yes & NP & NP & & \\
\hline 67 & MLGMD & Sporadic/NA & NP & NP & & \\
\hline 68 & SLGMD & Sporadic/NA & NP & NP & & \\
\hline 69 & SLGMD & Sporadic/NA & NP & NP & & \\
\hline
\end{tabular}

SLGMD denotes severe limb-girdle muscular dystrophy, MLGMD denotes mild limb-girdle muscular dystrophy and SLGMD+CM denotes severe limbgirdle muscular dystrophy with cardiomyopathy. Presence or absence of consanguinity is indicated by yes or no. NA indicates that the information is not available. For western blot results, absence or reduced level of protein is indicated by 0 or $\downarrow$, respectively. For mutation results: fs, frameshift; ND, not determined. '?' is to indicate that mutation consequence on protein production is unknown. The nucleotide and amino acids are numbered according to the translational reading frames deduced from sequences available in http://genome.ucsc.edu/ and http://www.dmd.nl/.

(iii) reduced level of $\alpha$ - and absence of $\gamma$-SG (8 patients), and (iv) reduced levels of $\alpha$ - and $\gamma$-SG (11 patients). To identify disease-causing mutations, DNA samples from these patients were used to amplify by PCR all exons of $\alpha-, \beta$, $\gamma$-, and $\delta$-SG genes and analyze by sequencing amplified PCR products. Such DNA-based analyses were also carried out for the other 21 patients included in this study and for whom muscle-biopsy specimens were not available. In a subsequent step, patients for whom either no mutation, or mutation of only one allele was detected, SG genes were further investigated by multiplex QF-PCR (or real-time quantitative PCR) to look for copy number changes of $\alpha$ - and $\gamma$-exons, and RT-PCR to search for qualitative anomalies of SG transcripts.

In total, mutations were detected in 57/69 (82.6\%) patients (Table 1), though homozygous or compound heterozygous status was identified in only 46 (67\%) patients. The status of these patients who had mutations of both SG gene alleles was further confirmed by tests on genomic DNA from both their parents and, when available, healthy and affected siblings. In each case, their parents were heterozygous for one of the two identified mutant alleles, and for familial cases identical genotypes were found in affected siblings. In one patient (1/47), double heterozygous mutations in $\beta$ - and $\delta$-SG genes were identified (c.10-22_33+?dup in the $\beta$-SG gene and c. $451 \mathrm{~T}>\mathrm{G}$ in the $\delta$-SG gene) (Table 2). Among the 46 patients with mutations of both alleles, we observed 26 (56.5\%) cases of $\alpha$-sarcoglycanopathy, 8 (17.3\%) cases of $\beta$-sarcoglycanopathy, and 12 (26\%) cases of $\gamma$-sarcoglycanopathy. For the 22 remaining patients, either mutation of only one allele (10 patients) or no mutation in the four SG genes (12 patients) was identified. Seven out of these 22 patients were from consanguineous families, and in 4 of them only one mutant allele was identified.

For the group of patients for whom western blot analysis showed abnormal profiles for $\alpha$ - and $\gamma$-SG proteins, mutations of both SG gene alleles were detected in 36 of the 48 patients (75\%). In five patients (patients $8,29,41$, 45 , and 47), only one mutant allele was identified. For the remaining seven patients (14.6\%), no mutation in the four SG genes was found. Distribution and type of mutations in the different SG genes are indicated in Table 2. In the subgroup of patients for whom muscle biopsy was not available, mutations of both SG gene alleles were identified in $11 / 21$ patients $(52 \%)$, mutation of only one allele was identified in 5 patients, and no mutation was identified in the remaining 5 patients (Table 1 ).

\section{Distribution and type of mutations identified in SG genes}

Among the patients with mutations in $\alpha$-SG gene (26 patients), 18 (69.2\%) were compound heterozygous and a total of 23 different mutations were identified, 10 of which, such as the deletion encompassing exons 7 and 8, were described for the first time in this study (Table 2). For patients 17 and 19 (Table 2), the deletion of exons 7 and 8 , revealed by QF-PCR, was confirmed by RT-PCR analysis of SGCA mRNA (Figure 2). This analysis showed also the presence of a significant imbalance between levels of transcripts corresponding to the normal and the mutated out-of-frame transcript lacking exons 7 and 8 (Figure 2). This imbalance is probably the result of the nonsensemediated RNA decay (NMD) process that detects and 


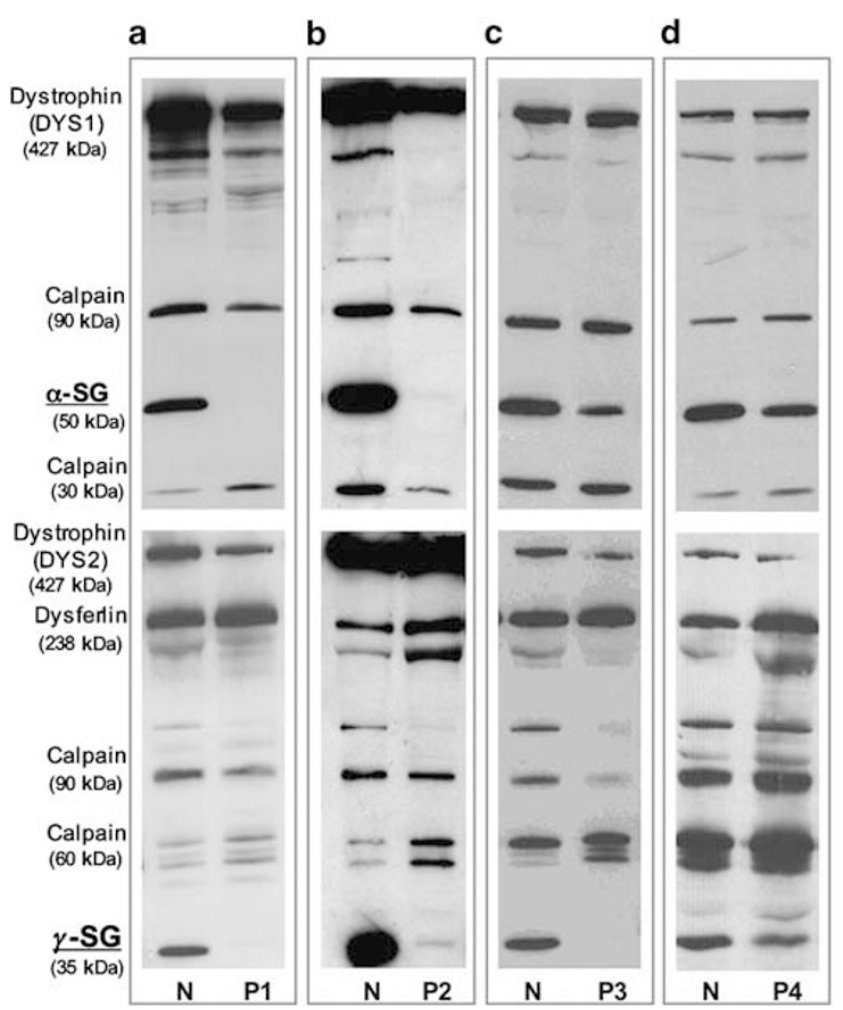

Figure 1 Illustration of the four abnormal multiplex western blot profiles corresponding to quantitative abnormalities of $\alpha$ - and $\gamma$-SG proteins. (a) Profile: $\alpha=0 \gamma=0$, absence of the two SG proteins in a patient with LGMD2C (P1). (b) Profile: $\alpha=0 \gamma \downarrow$, absence of $\alpha$-SG and reduced level of $\gamma$-SG in a patient with LGMD2D (P2). (c) Profile: $\alpha \downarrow$ $\gamma=0$, reduced level of $\alpha$-SG and absence of $\gamma$-SG in a patient with LGMD2C (P3). (d) Profile: $\alpha \downarrow \gamma \downarrow$, reduced level of both $\alpha$ - and $\gamma$-SG proteins in a patient with LGMD2D (P4).

degrades RNA transcripts containing nonsense and frameshift mutations. ${ }^{29,30}$

Though at first sight mutations in $\alpha$-SG gene appear to be distributed throughout the gene, it is worth mentioning the relative high frequency of mutations in exon 3 (13/26; $50 \%$ ) and in exon $5(6 / 26 ; 23 \%)$ (Table 2 and Figure 3$)$.

Mutations in the $\beta$-SG gene were identified in eight patients of this cohort, and two of them were compound heterozygous (Table 2). Seven of the nine mutations have not been previously described, and two of them correspond to partial duplications of exon 1 (c.4 -22_4dup26 and c.10-22_33+?dup). The first duplication was observed in patient 32 (Table 2) for whom the western blot analysis of muscular proteins showed an absence of $\alpha$-SG and reduced level of $\gamma$-SG (Supplementary Figure 1). Among the two other mutations there is also a third partial duplication of exon 1 (c.10 -22_10dup32) that has been previously reported. ${ }^{25,31}$ Duplicated sequences were of different size $(26,32$, and $>55 \mathrm{bp}$, as the third duplication encompasses exon 1 and its $3^{\prime}$ end was not defined).

Mutations in the $\gamma$-SG gene were identified in $12 / 48$ patients (25\%) (Table 2$)$. One-third (4/12) of these patients were compound heterozygous and 5 of the 10 different mutations detected in these patients have not been previously described. Among the 5 mutations, 4 correspond to different exonic deletions that were found in $9 / 12(75 \%)$ of the patients with $\gamma$-sarcoglycanopathy. Six of these patients were homozygous for deletions of exon 1 (one patient), exons 5 and 6 (two patients), exon 7 (one patient), and exon 3 (two patients) (Supplementary Figure 2 ), and three were compound heterozygous with deletions of exon 7 (two patients), or the whole $\gamma$-SG gene (one patient). This latter abnormality was also previously described. ${ }^{32,33}$ Patients for whom total RNA extracted from muscle biopsy was available, exonic deletions were confirmed by RT-PCR analysis of SGCG mRNA (Table 2 and Supplementary Figure 2).

\section{Patients with monoallelic, or without mutations: RT-PCR and genotyping data}

Among the 22 remaining patients, for whom analysis of SG genes did not allow to identify mutations of both alleles, quantitative abnormalities of $\alpha$ - and $\gamma$-SG proteins were pointed out in 12 patients ( 5 with one mutant allele and 7 with no mutation) by multiplex western blot analysis of muscle proteins (Table 1). For these patients we analyzed, by RT-PCR and sequencing, SG transcripts, but no additional qualitative abnormality was detected. Also, for five probands, from consanguineous families, including those with abnormal western blot profile (patients 45,47 , and 58 , Table 2), homozygosity of the SG regions was excluded by segregation analysis of polymorphic microsatellite markers located within or in the vicinity of the four SG loci. For one proband (patient 47 with a heterozygous exon 8 deletion in the $\gamma$-SG), segregation analysis was performed for the whole family, including the parents, and none of the affected siblings presented a homozygous region for any of the four SG genes (Figure 4).

\section{Discussion}

In this study, we report the analysis of SG genes in a large series of 69 undiagnosed LGMD patients with clinical, biological, and histological features compatible with the diagnosis of sarcoglycanopathies. For 48 patients, muscle protein analysis using multiplex western blot showed partial or complete deficiency of $\alpha$ - and $\gamma$-SG. In this latter group of patients, we were able to identify mutations of both SG gene alleles in about 75\% (36/48) of the cases, while mutation detection rate did not exceed 52\% $(11 / 21)$ in the group of patients for whom the diagnosis was not supported by the analysis of muscle proteins. As previously reported, ${ }^{25,34}$ these results clearly indicate that proteinbased strategy, followed by molecular analysis, is probably the most logical and efficient way to approach diagnosis of sarcoglyconopathies. The previous studies using SG immunohistochemistry and $\alpha$-SG immunoblotting to 


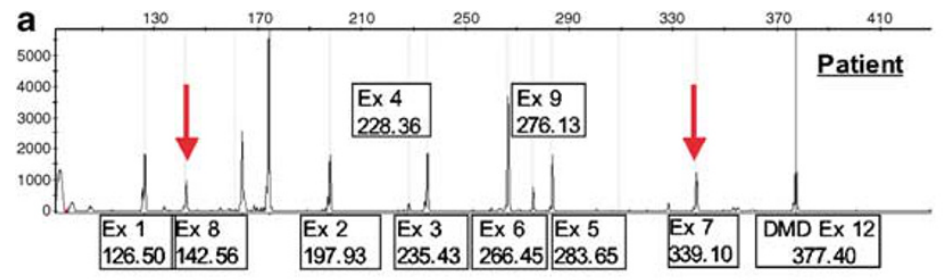

b
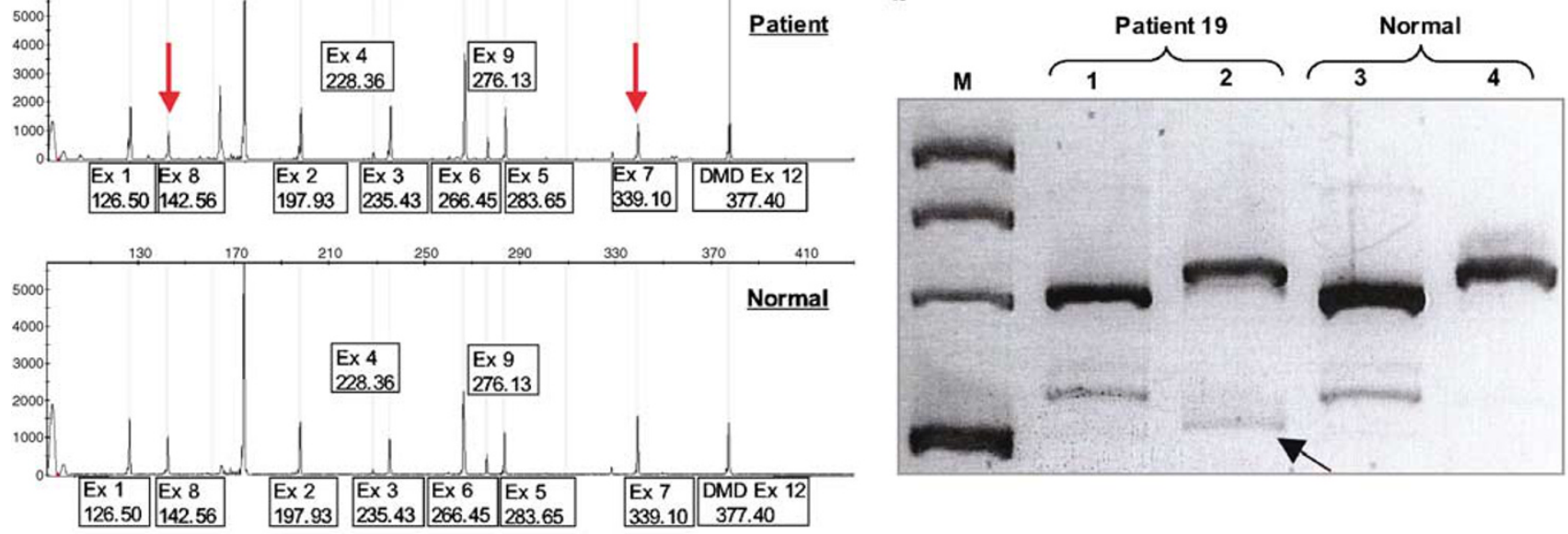

C

Exon 7

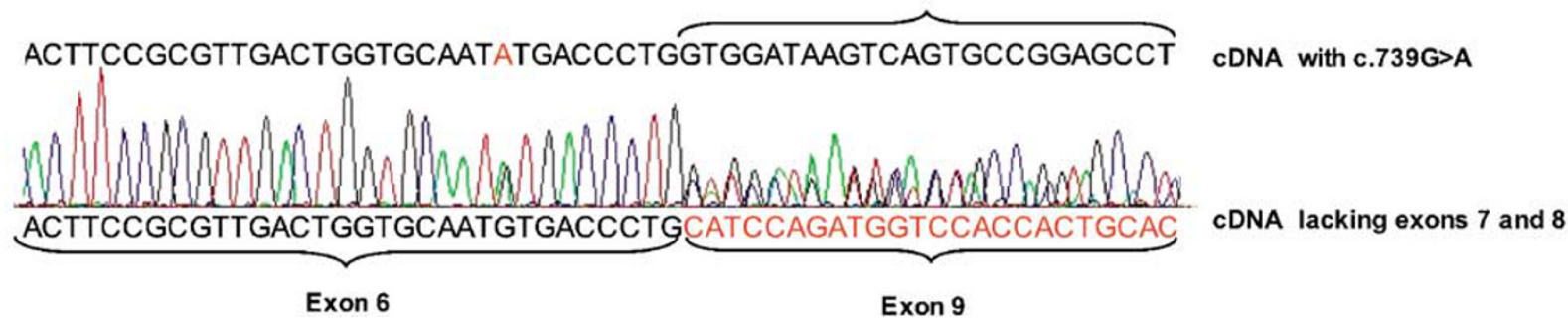

Figure 2 Heterozygous deletion of exons 7 and 8 of SGCA gene (patient 19, Table 2). (a) Multiplex QF-PCR analysis of SGCA exons showing a reduction of the peaks of exons 7 and 8 compared to normal. (b) RT-PCR results showing the presence of the normal transcript and the transcript lacking exons 7 and 8 (indicated by an arrow). M: size marker. 1 and 3: RT-PCR-amplified CDNA fragment covering exons 1-4 (line 1: control and 3: patient), 2 and 4: cDNA covering exons 5-9 (line 2: control and 4: patient). (c) Partial sequence of SGCA cDNAs bearing the heterozygous missense mutation and lacking exons 7 and 8. Peaks from the two alleles appear with same intensity because sequence analysis was performed by pooling similar amounts of purified RT-PCR fragments (corresponding to normal and mutated fragments) that were separated by electrophoresis on an agarose gel.

identify potential sarcolycanopathy patients reported mutation detection rates of about $58(29 / 50)^{34}$ to $70 \%$ $(12 / 17) .{ }^{25}$ Rates reported in these studies included patients for whom only one allele mutation concerning one of the SG genes was identified. However, irrespective of mutation detection rate differences, these studies consistently highlight that not all patients ascertained with absent or reduced levels of $\gamma$ - and/or $\alpha$-SG proteins in muscle biopsy can be shown to have a mutation in one of the SG genes by currently used standard techniques. In this study, western blot analysis showed muscle protein profile concordant with sarcoglycanopathy in seven patients with no mutation, and in five patients with only one mutation in one of the four SG genes. In these latter patients, it is unlikely that monoallelic mutations in SG genes are responsible for LGMD phenotypes. Indeed, two of these mutations, c.341C $>\mathrm{T}$ in $\beta$-SG and c.525delT in $\gamma$-SG, were also found in a homozygous state in several patients. The c.525delT mutation is a common homozygous mutation among patients with $\gamma$-sarcoglycanopathy, and the c.341C $>\mathrm{T}$ in $\beta$-SG was identified in two homozygous patients of this study (patients 31 and 33, Table 2). For the remaining three other patients with monoallelic mutations (patients 8,41 , and 47 , Table 2 ), though homozygosity was not previously reported, their pathogenic effects in heterozygous patients can be excluded because they were inherited from one of their healthy parents (data not shown). For such patients with monoallelic mutations, it is usual to hypothesize that mutations involving parts of SG genes (such as intronic or promotor regions) that have not been analyzed cannot be excluded. However compelling evidence, which includes the absence of deletions/duplications searched by QF-PCR, the absence of intronic splice mutations searched by RT-PCR, and the absence in consanguineous families of homozygosity of polymorphic markers corresponding to SG gene regions, allows to exclude implication of SG genes in LGMD phenotypes diagnosed in these patients. Basically, the identification of SG-deficient patients without mutations (homozygous, compound heterozygous, or double heterozygous status) in any of the four SG genes strongly indicates the implication of an as yet unknown gene(s) defect(s), primary abnormalities of which lead to 

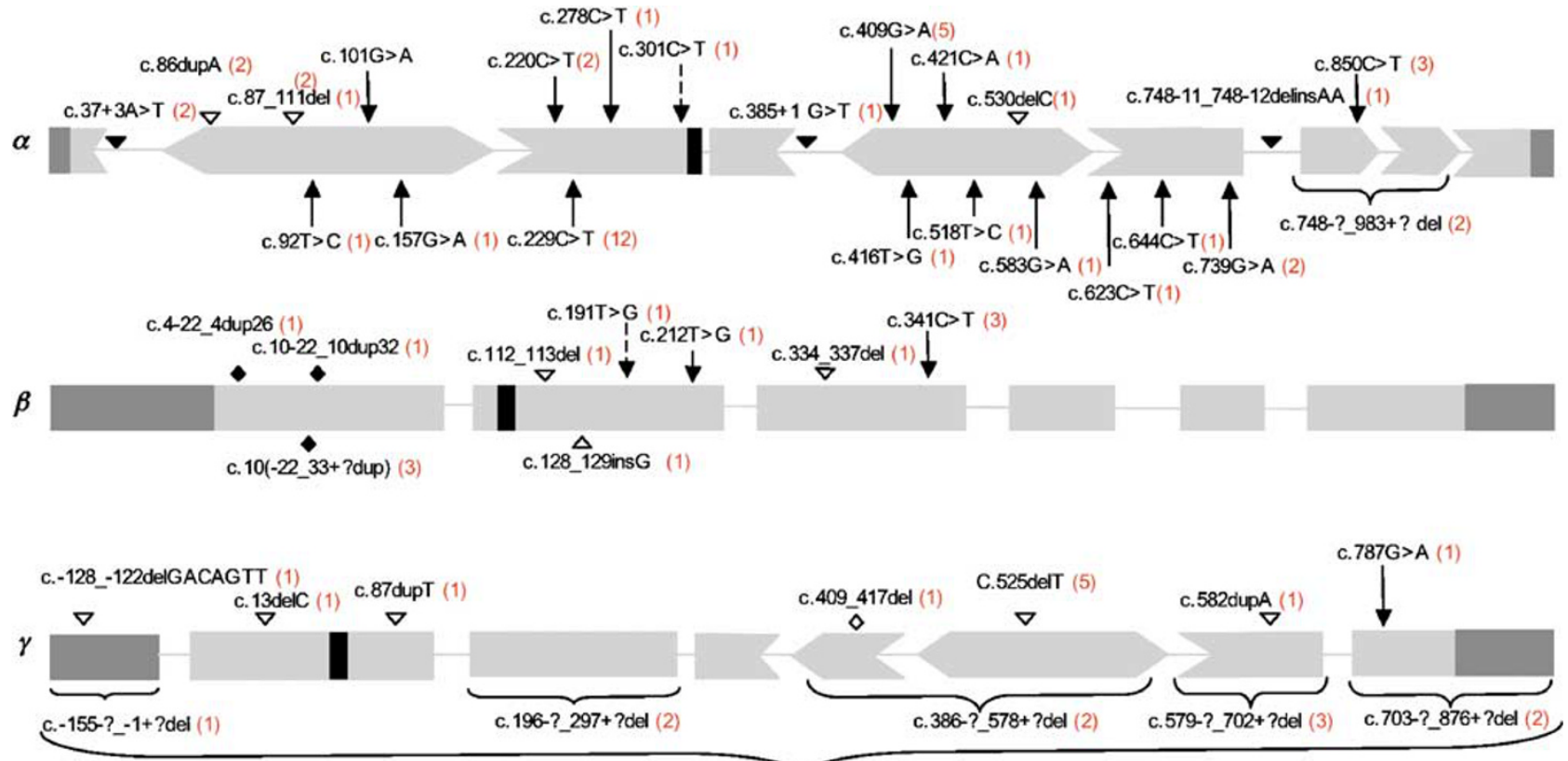

c.-155-?_876+?del (1)

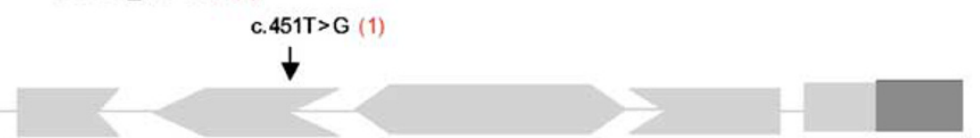

$\delta$

Figure 3 Spectrum of mutations in the four SG genes. Missense, nonsense, frameshift, and splice mutations, inframe and exonic deletions as well as inframe duplications, are represented by $\downarrow, \nabla, \nabla, \nabla, \diamond, \downarrow$, and $\downarrow$, respectively. To accommodate number and distribution of mutations, size of exons is not represented at scale. Dark gray exonic regions represent the $5^{\prime}$ and $3^{\prime}$ non-coding sequences, whereas black ones represent sequences coding for transmembrane domains. Numerals within parentheses indicate, for each mutation, the number of mutated alleles.

the secondary SG deficiency. Ongoing efforts aiming to perform whole genome studies of consanguineous cases and analysis of candidate genes in this potentially homogeneous group of patients/families with reduced level of SG proteins should allow some progress in the delineation of molecular causes involved in these undiagnosed disorders.

It is well established that mutations in any of the SG genes are associated with partial or total loss of all components of the muscle SG complex, and sometimes reduction of dystrophin level in muscle as well. ${ }^{18}$ Therefore, to guide diagnosis investigations, in our diagnostic laboratory at Cochin Hospital, protein extracts from muscle biopsy specimens are systematically analyzed by multiplex western blot that include testing of $\alpha$ - $(50 \mathrm{kDa})$ and $\gamma$-SG $(35 \mathrm{kDa})$ proteins and patients with complete loss or reduced level of $\alpha$ - and $\gamma$-SG were classified into four groups, according to their western blot profiles (see Materials and methods, and Results sections). Though with any primary SG protein involvement, the pattern of secondary deficiencies can be strikingly variable, it is interesting to highlight the following findings. (i) Patients with a profile that corresponds to an absence of both $\alpha$ - and $\gamma$-SG proteins are frequently mutated for the $\alpha$-SG gene. Indeed 10 patients presenting this profile (10 of 23), and for whom mutations of both SG gene alleles were identified (10 of 16), were found mutated for the $\alpha$-SG gene (Table 1). (ii) Also, as previously described, ${ }^{25,35}$ we noticed that all patients with established $\gamma$-sarcoglycanopathy (mutations of both $\gamma$-SG gene alleles) have complete absence of $\gamma$-SG protein. In this study, none of them presented the profiles corresponding to an absence of $\alpha$ - and reduced level of $\gamma$ - or with reduced level of both SG proteins. (iii) Patients with a reduced level of $\gamma$-SG are either mutated for $\alpha$ - or $\beta$-SG genes. On the basis of these findings and as illustrated in Figure 5, it appears that $\alpha$ - and $\gamma$-SG expression profiles, assessed by western blot, are very useful criteria that could be integrated in diagnostic strategies aiming to reach precise diagnosis of the type of sarcoglycanopathy.

Distribution and type of mutations in the SG genes (Table 2 and Figure 3) showed that of the 57 patients with mutations of one or both alleles, 14 were found by multiplex QF-PCR to be homozygous or heterozygous for exon deletions of $\alpha$ - or $\gamma$-SG genes. Occurrence of deletions in $\alpha$ - and $\gamma$-SG genes contrasts with the absence of deletions in the $\beta$ - and $\delta$-SG genes, though search for deletions in these genes was performed in patients for whom only one mutant allele, or no mutation, was identified. To our knowledge, rare exon deletions have been reported for the 


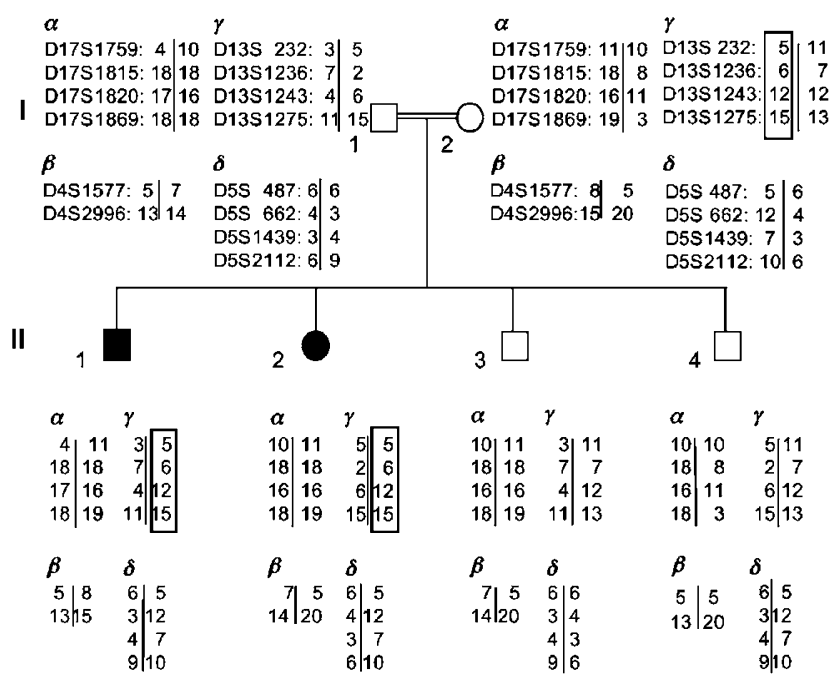

Figure 4 Segregation results and haplotypes corresponding to microsatellite markers covering SGCA (chromosome 17), SGCG (chromosome 13), SGCB (chromosome 4), and SGCD (chromosome 5) loci. Note the absence of a common haplotype in the parents and therefore homozygosity in the affected patients for all SG gene regions in this consanguineous family of patient $47\left(\mathrm{II}_{1}\right.$ and his brother $\left.\mathrm{II}_{2}\right)$ for whom a heterozygous deletion of $\gamma$-SG's exon 8 was detected.

$\gamma$-SG gene, ${ }^{32,36,37}$ but such abnormalities have not yet been described for the $\alpha$-SG gene. In this study, two patients (patients 17 and 19, Table 2) were found compound heterozygous for a deletion encompassing exons 7 and 8 on one allele with a missense mutation on the other allele (c.229C > T and c.739G >A, respectively). Deletion in these two patients was detected by QF-PCR, then confirmed by RT-PCR analysis of $\alpha$-SG transcripts using total RNA extracted from muscle biopsies (Figure 2). In addition to the missense mutations, these analyses showed the presence of an $\alpha$-SG transcript lacking exons 7 and 8 that was weakly expressed. This imbalance between the normal and the mutated allele could be the consequence of mutated mRNA's destruction by the NMD.

For $\gamma$-SG gene, we detected 12 patients with exon deletions (Table 2). Six of them were found homozygous for deletions concerning exon 1 , exon 3 , exons 5 and 6 , or exon 7 . The remaining six patients were found heterozygous for deletions concerning one of the exons 3, 7, and 8 or the entire gene (Table 2). These results strongly indicate that this type of mutations represents frequent events and therefore screening for such mutations should be implemented in diagnostic strategies of sarcoglycanopathies (Figure 5).

Among the 11 patients with mutations in the $\beta$-SG gene, 5 were found to bear partial duplications of exon 1 (Table 2 , Figure 3 and Supplementary Figure 1). One of these duplications (c.10 -22_10dup32) was previously reported by Boito and colleagues. ${ }^{25,31}$ It is worth mentioning that the duplicated sequences identified in four of the five unrelated patients described in this study (Table 2), as well as the two previously reported ones, appear to be inserted at a potential common site: +10 downstream to the ATG start codon. Although the duplicated sequence, observed in the fifth patient of our study, was inserted at +4 downstream to the ATG start codon, all the duplicated sequences have a $5^{\prime}$ end that corresponds to the sequence at -22 upstream to the ' $\mathrm{A}$ ' of the start codon (Supplementary Figure 1). These results strongly indicate that this region is unstable and may be a hotspot for mutations and more particularly for duplications, most probably because of its high $\mathrm{C} / \mathrm{G}$ content and the presence of a duplicated (CGG) sequence at position -22 (that corresponds also to the $5^{\prime}$ end of the duplicated sequence) and +10 (that corresponds to the potential site of insertion) upstream and downstream to the ' $\mathrm{A}$ ' of the start codon, respectively.

$\delta$-SG gene mutations were identified in only one patient of our cohort (patient 57, Table 2). This patient carried two mutated alleles: one affecting the $\delta$-SG gene and the other one the $\beta$-SG gene. The $\delta$-SG mutation was a known missense mutation in exon 6 , changing the wild-type serine to alanine (S151A). The $\beta$-SG mutation corresponds to a duplication in exon 1: (c.10-22_33+?dup), also detected in a compound heterozygous patient affected with $\beta$-sarcoglycanopathy. The very low frequency of mutations in $\delta$-SG gene, reported in this study, contrasts with the $14 \%$ (5 of 35 patients) found in a Brazilian cohort, $^{35}$ though one of the mutations (c.656delC) was a recurrent one and was detected four times. The different ethnic background of the patients may be a relevant fact to explain the heterogeneity of $\delta$-sarcoglycanopathy mutation rates among the various studies.

The patient with double heterozygous mutations manifested at 3 years of age muscle weakness, complicated with cardiomyopathy at the age of 13 years. Though this genotype (double heterozygous mutations) represents a potential molecular cause of the patient's muscle phenotype, one cannot rule out the presence of an additional mutation (undetectable by the performed investigations) on either one of the second allele of $\beta$-, or $\delta$-SG genes.

Interestingly, the $\delta$-SG mutation (c.451T $>$ G; S151A) detected in this study has been described for the first time in a family with five siblings affected with dilated cardiomyopathy. ${ }^{38}$ None of the unaffected members of the family and none of the 200 control individuals had this abnormal variation changing from a polar to an unpolar amino acid. The patients with the c.451T $>\mathrm{G}$ mutation described in the report of Tsubata et $a l^{38}$ were heterozygous, they were all symptomatic with congestive heart failure at young age, 4/5 had sudden cardiac death, and neuromuscular examination was normal for all of them. The authors suggested that this $\delta$-SG mutation has a dominant negative effect. ${ }^{10}$ All together, these data suggest that mutation in $\delta$-SG gene is likely to be responsible for the DCM, and muscle weakness could result from potential 


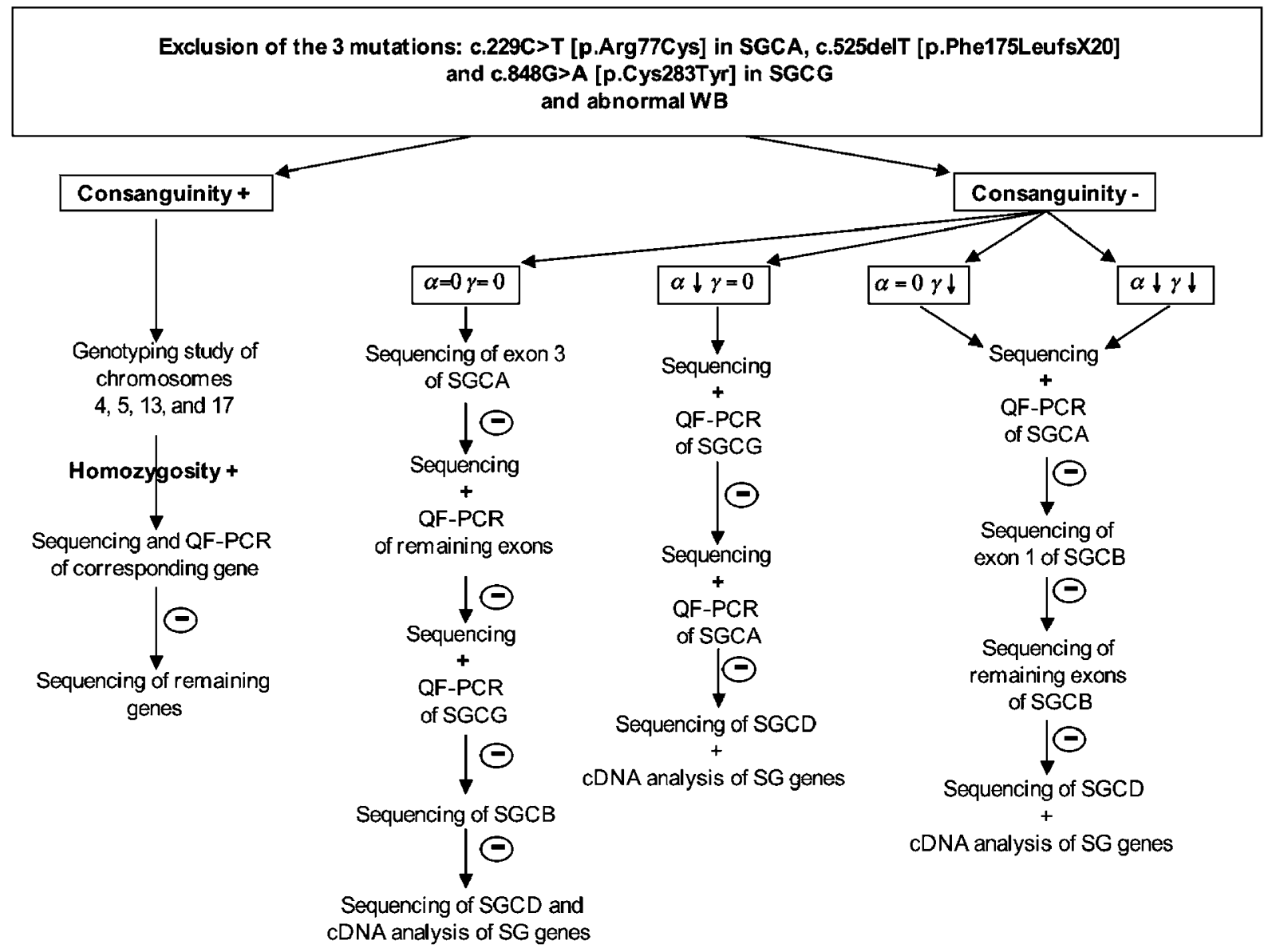

Figure 5 Diagnostic strategy of sarcoglycanopathies based on findings highlighted in this study, including quantitative abnormalities of $\alpha$ - and $\gamma$-SG proteins detected by multiplex western blot. Investigations proposed in this strategy are undertaken after exclusion of the three most frequent mutations, known in France: c.229C > T in SGCA, c.525delT and c.848G >A in SGCG. Although CDNA analysis of SG genes from patient's muscle biopsies and genomic screening of SGCD gene, carried out in patients with only one mutated allele or without mutation, did not reveal additional mutations, these analyses are still necessary for an exhaustive diagnostic strategy.

deleterious synergic effect on muscle function of $\beta$ - and $\delta$-SG mutations.

We, like others, found that clinical phenotypes of patients with primary sarcoglycanopathy are heterogeneous and cover a clinical spectrum that is similar to the one resulting from mutations in the DMD gene, though Duchenne- and Becker-like muscular dystrophy are the most frequent phenotypes. In this study, the diagnosis of sarcoglycanopathy was confirmed in 52.4\% $(11 / 21)$ of the mild phenotypes (LGMD similar to Becker muscular dystrophy), in $71.4 \%$ (30/42: $16 \alpha-, 4 \beta$-, and $10 \gamma$-SG gene mutations) of the severe forms (Duchennelike muscular dystrophy) without cardiomyopathy and in $100 \%$ of patients with severe form of muscular dystrophy associated with cardiomyopathy (6/6 cases: $4 \alpha, 1 \beta, 1$ $\gamma$; Table 2). In addition, it is interesting to point out that most patients presenting a slight decrease of dystrophin $(10 / 12)$ have severe forms of LGMD. This feature is not systematically associated with severe forms, as it was observed in only 10 of the 31/48 severely affected patients; however, its prognostic value may well be significant and further studies are required to confirm this correlation.

In conclusion, molecular diagnosis of sarcoglycanopathies is still a difficult task, as large spectrum of mutations could be found in each of the SG genes. In this study, we show that protein analysis by multiplex western blot can improve molecular diagnostic strategy that must include search for exon deletions. Also, identification of five patients with partial duplications of exon 1 of the $\beta$-SG gene strongly suggests that exon 1 is a hotspot region for mutations, and that it should be cautiously analyzed. Finally, compelling evidence suggest an implication in sarcoglycanopathy-like disorders of others genes, defects of which may influence expression or stability of the SG complex. 


\section{Acknowledgements}

We express our thanks for the patients and families for their participation in the study, and the physicians for referring patients to our diagnostic laboratory. We also thank all members of the laboratoire de Biochimie Génétique et Moléculaire, and the Cell Bank of Cochin Hospital for their technical help. This study was supported by grants from AP-HP, INSERM, FRM and AFM.

\section{References}

1 Lim LE, Campbell KP: The sarcoglycan complex in limb-girdle muscular dystrophy. Curr Opin Neurol 1998; 11: 443-452.

2 Ervasti JM, Campbell KP: Membrane organization of the dystrophin-glycoprotein complex. Cell 1991; 66: 1121-1131.

3 Cohn RD, Campbell KP: Molecular basis of muscular dystrophies. Muscle Nerve 2000; 23: 1456-1471.

4 Rando TA: The dystrophin-glycoprotein complex, cellular signaling, and the regulation of cell survival in the muscular dystrophies. Muscle Nerve 2001; 24: 1575-1594.

5 McNally EM, Yoshida M, Mizuno Y, Ozawa E, Kunkel LM: Human adhalin is alternatively spliced and the gene is located on chromosome 17q21. Proc Natl Acad Sci USA 1994; 91: 9690-9694.

6 Azibi K, Bachner L, Beckmann JS et al: Severe childhood autosomal recessive muscular dystrophy with the deficiency of the $50 \mathrm{kDa}$ dystrophin-associated glycoprotein maps to chromosome 13q12. Hum Mol Genet 1993; 2: 1423-1428.

7 Bonnemann CG, Modi R, Noguchi S et al: Beta-sarcoglycan (A3b) mutations cause autosomal recessive muscular dystrophy with loss of the sarcoglycan complex. Nat Genet 1995; 11: 266-273.

8 Lim LE, Duclos F, Broux O et al: Beta-sarcoglycan: characterization and role in limb-girdle muscular dystrophy linked to $4 \mathrm{q} 12$. Nat Genet 1995; 11: 257-265.

9 Noguchi S, McNally EM, Ben Othmane K et al: Mutations in the dystrophin-associated protein gamma-sarcoglycan in chromosome 13 muscular dystrophy. Science 1995; 270: 819-822.

10 Nigro V, Piluso G, Belsito A et al: Identification of a novel sarcoglycan gene at $5 \mathrm{q} 33$ encoding a sarcolemmal $35 \mathrm{kDa}$ glycoprotein. Hum Mol Genet 1996; 5: 1179-1186.

11 Nigro V, de Sa Moreira E, Piluso G et al: Autosomal recessive limbgirdle muscular dystrophy, LGMD2F, is caused by a mutation in the delta-sarcoglycan gene. Nat Genet 1996; 14: 195-198.

12 Roberds SL, Leturcq F, Allamand V et al: Missense mutations in the adhalin gene linked to autosomal recessive muscular dystrophy. Cell 1994; 78: 625-633.

13 Moreira ES, Vainzof M, Suzuki OT, Pavanello RC, Zatz M, PassosBueno MR: Genotype-phenotype correlations in 35 Brazilian families with sarcoglycanopathies including the description of three novel mutations. J Med Genet 2003; 40: E12.

14 Ben Othmane K, Speer MC, Stauffer J et al: Evidence for linkage disequilibrium in chromosome 13-linked Duchenne-like muscular dystrophy (LGMD2C). Am J Hum Genet 1995; 57: $732-734$

15 Piccolo F, Jeanpierre M, Leturcq F et al: A founder mutation in the gamma-sarcoglycan gene of gypsies possibly predating their migration out of India. Hum Mol Genet 1996; 5: 2019-2022.

16 Carrie A, Piccolo F, Leturcq F et al: Mutational diversity and hot spots in the alpha-sarcoglycan gene in autosomal recessive muscular dystrophy (LGMD2D). J Med Genet 1997; 34: 470-475.

17 Bushby KM: The limb-girdle muscular dystrophies: diagnostic guidelines. Eur J Paediatr Neurol 1999; 3: 53-58.

18 Bushby KM: The limb-girdle muscular dystrophies - multiple genes, multiple mechanisms. Hum Mol Genet 1999; 8: 1875-1882.
19 Bushby KM: Making sense of the limb-girdle muscular dystrophies. Brain 1999; 122 (Pt 8): 1403-1420.

20 Comerlato EA, Scola RH, Werneck LC: Limb-girdle muscular dystrophy: an immunohistochemical diagnostic approach. Arq Neuropsiquiatr 2005; 63: 235-245.

21 Politano L, Nigro V, Passamano L et al: Evaluation of cardiac and respiratory involvement in sarcoglycanopathies. Neuromuscul Disord 2001; 11: 178-185.

22 van der Kooi AJ, de Voogt WG, Barth PG et al: The heart in limb girdle muscular dystrophy. Heart 1998; 79: 73-77.

23 Yamada H, Saito F, Fukuta-Ohi H et al: Processing of beta-dystroglycan by matrix metalloproteinase disrupts the link between the extracellular matrix and cell membrane via the dystroglycan complex. Hum Mol Genet 2001; 10: $1563-1569$.

24 Anderson LV: Optimized protein diagnosis in the autosomal recessive limb-girdle muscular dystrophies. Neuromuscul Disord 1996; 6: 443-446.

25 Boito C, Fanin M, Siciliano G, Angelini C, Pegoraro E: Novel sarcoglycan gene mutations in a large cohort of Italian patients. J Med Genet 2003; 40: e67.

26 Anderson LV, Davison K: Multiplex western blotting system for the analysis of muscular dystrophy proteins. Am J Pathol 1999; 154: 1017-1022.

27 Deburgrave N, Daoud F, Llense S et al: Protein- and mRNA-based phenotype-genotype correlations in DMD/BMD with point mutations and molecular basis for BMD with nonsense and frameshift mutations in the DMD gene. Hum Mutat 2007; 28: $183-195$.

28 Yau SC, Bobrow M, Mathew CG, Abbs SJ: Accurate diagnosis of carriers of deletions and duplications in Duchenne/Becker muscular dystrophy by fluorescent dosage analysis. J Med Genet 1996; 33: 550-558.

29 Hentze MW, Kulozik AE: A perfect message: RNA surveillance and nonsense-mediated decay. Cell 1999; 96: 307-310.

30 Wagner E, Lykke-Andersen J: mRNA surveillance: the perfect persist. J Cell Sci 2002; 115: 3033-3038.

31 Fanin M, Melacini P, Boito C, Pegoraro E, Angelini C: LGMD2E patients risk developing dilated cardiomyopathy. Neuromuscul Disord 2003; 13: 303-309.

32 Bonnemann CG, Wong J, Jones KJ et al: Primary gammasarcoglycanopathy (LGMD 2C): broadening of the mutational spectrum guided by the immunohistochemical profile. Neuromuscul Disord 2002; 12: 273-280.

33 Nowak KJ, Walsh P, Jacob RL et al: Severe gamma-sarcoglycanopathy caused by a novel missense mutation and a large deletion. Neuromuscul Disord 2000; 10: 100-107.

34 Duggan DJ, Hoffman EP: Autosomal recessive muscular dystrophy and mutations of the sarcoglycan complex. Neuromuscul Disord 1996; 6: 475-482.

35 Vainzof M, Passos-Bueno MR, Pavanello RC, Marie SK, Oliveira AS, Zatz M: Sarcoglycanopathies are responsible for $68 \%$ of severe autosomal recessive limb-girdle muscular dystrophy in the Brazilian population. J Neurol Sci 1999; 164: 44-49.

36 White SJ, Uitte de Willige S, Verbove D et al: Sarcoglycanopathies and the risk of undetected deletion alleles in diagnosis. Hum Mutat 2005; 26: 59.

37 Duncan DR, Kang PB, Rabbat JC et al: A novel mutation in two families with limb-girdle muscular dystrophy type 2C. Neurology 2006; 67: 167-169.

38 Tsubata S, Bowles KR, Vatta $\mathrm{M}$ et al: Mutations in the human delta-sarcoglycan gene in familial and sporadic dilated cardiomyopathy. J Clin Invest 2000; 106: 655-662. 